cannot be controlled either by any existing statute or under by-laws. Thus, whereas a reasonable width of street may be secured by means of a by-law, there is absolutely no provision to prevent the erection of houses of such a height as effectually to exclude sunlight, and so it comes to pass that windows open, not on to bright, dry, open spaces, but into comparatively narrow thoroughfares which tend to remain damp and imperfectly lighted. Prof. Tyndall's experiments as to the arrestation of infusorial life by solar light should alone suffice to secure for the spaces about our dwellings ample exposure to the rays of the sun, for he has clearly shown that, after infecting certain sterilised infusions and exposing one set where no sun could reach them and another set to the influence of the sun, infusorial life was much more rapidly developed in the former than in the latter; and this notwithstanding the fact that the temperature of the flasks exposed to solar influence was far more favourable to the development of low forms of life than was the case as regards the others. It has also been decided by the law officers of the Crown that the height of rooms cannot be regulated either under any general statute or by means of a by-law. As to this, however, we note that $\mathrm{Mr}$. John Honeyman, a well-known architect, strongly advocated at the Congress the desirability of low ceilings in small houses, alleging that such an arrangement, by inducing economy in construction, facilities for warming, and other incidental advantages, would tend to prevent overcrowding and also add to the comfort of the lower classes. There can be no question that wherever the height of a room is such that the upper portion becomes a mere reservoir for overheated, stagnant, and vitiated air, and whenever adequacy of floor space per head of the occupants is sacrificed on account of an increased cubic space resulting from a high ceiling, then distinct harm results from the loftiness of the apartment; but, due regard being paid to ventilation by means of windows opening nearly up to the ceiling level and other contrivances, a reasonably high apartment has distinct advantages over many of the low ones which are now constructed.

Turning, however, to matters which are well within the control of sanitary authorities, the members of the Congress were unanimous in condemning the present system by which dwelling-houses are now constructed. Thus, instead of covering the ground surface of the sites of new houses with concrete so as to prevent both moisture and effluvia from any neighbouring leaky drain from ascending into the dwelling, the builders round about London and elsewhere either put their brick foundations directly on to the clay or other soil, or else they provide a material which can only be regarded as a make-shift in so far as imperviousness is concerned, and even this is only placed immediately beneath the house walls. Then again, pieces of tarred felt are inserted in the place of adequate damp courses, and so it comes to pass that, within a few months of occupation, the residents are, apart from other evils, exposed to one of the principal predisposing, if not exciting, causes of phthisis. As for drainage, this work can, as soon as completed, be hidden out of sight, and it is notorious how much illness has resulted, and how many lives have been sacrificed, to the want on the part of builders of the most elementary knowledge in connection with the construction and adequate ventilation of house drains.

In dealing with these and other allied subjects, the several speakers paid a tribute of praise to the Model By-laws which have been issued by the Local Government Board, and which in their annotated form fully explain, by means of diagrams and otherwise, how all the various health and other requirements may be most effectually provided. But even where such by-laws have been adopted, we fear they are in many instances not enforced; and evidence was given at the Congress to the effect that the principal offenders are themselves often members of the authorities whose duty it is to see the several provisions carried out. As long as this is the case, subordinate officers can hardly be expected to perform their duties efficiently, and the principal remedies needed are, firstly, by means of congresses, lectures to working men, and such measures, to spread broadcast, and in an easily acquired form, a knowledge as to the elements of house sanitation; and, secondly, a determination on the part of the public to elect as members of local authorities only those who have such knowledge and who will use it for the public benefit.

\section{THE ASTRONOMISCHE GESELLSCHAFT}

\section{[FROM OUR VIENNA CORRESPONDENT]}

THE meeting of the Astronomische Gesellschaft was held this year on September 14,15 , and 16 , in the Academy of Sciences in Vienna. There was a good attendance, and among others present we observed the astronomers Auwers of Berlin, Gould of Cordoba, Pickering of Cambridge, U.S., Elkin of the Cape, Lœwy and Janssen of Paris, Foli of Liége, Gylden of Stockholm, Engstroem of Lund, Oudemans of Utrecht, Foerster of Berlin, Voyel of Potsdam, Gautier, sen. and jun., of Geneva, Thiele and Pechule of Copenhagen, Wagner, Hasselberg, and Dubiago of Pulkova, Bruhns of Leipzig, Wolf and Schönfeld of Bonn, Gruey of Besançon. England was represented by Prof. G. Forbes. The head of the Ministry of Public Instruction in Austria, Dr. Siedler, having welcomed the assembly in the name of the Government, the president, Prof. A. Auwers, briefly addressed the Congress. For the second time, he said, the Congress held its sittings in those halls. The first time they met there they found in this building the old observatory. They now beheld an institution which in magnificence was hardly matched by any other institution in the world and surpassed by none. The President then thanked the Government for their friendly welcome, and the assembly for the large attendance present. The subjects which were the order of the day were then taken up. From the report of President Auwers on the great zone undertaking, it appeared that the observations of all the observatories in connection therewith might be deemed completed, so that next year they would be in a position to enter on the printing of the official catalogue. It was further shown that the preparations for extending this enterprise to the south as far as $23^{\circ}$ or thereabout, southern declination, an object which for several years had been in contemplation, were so far advanced that the scheme might now be considered as secured. In the course of the three sittings of the Society a large number of interesting addresses were given and demonstrations made, most of them followed by lively discussions.

Prof. Bruhns spoke on astronomical refractions, and on the formulæ according to which from the observed refraction the law of reduction of temperature in the atmosphere night be determined. Gylden referred to investigations he had made on the subject of the perturbation theory of planets, and to the labours of the Stockholm Observatory towards drawing up tables of planets in accordance with his theory. Prof. Weiss (Vienna) produced the two printed volumes of the annals of the Vienna Observatory, as also the first sheets of his new edition of "The Wonders of the Heavens" by Littrow, and showed drawings of Jupiter and Saturn, executed by help of the 27 -inch instrument of the Vienna Observatory, together with drawings of lunar maculæ taken by means of the I2-inch instrument of the same observatory. Photographs of the sun's corona taken in full daylight, sent by Dr. Huggins and laid before the meeting by 
Prof. Weiss, were received with much approval. Dr. Elkin reported parallax determinations of southern stars executed by him and Gill at the Cape, especially that of $a$ Centauri, which might be fixed at about $75 \mathrm{sec}$., and that of Sirius, which increased to $4 \mathrm{sec}$.

Pickering drew attention to photometric investigations carried out at the observatory of Harvard College. Janssen (Meudon) spoke on the observations which had been made in connection with the sun's eclipse of May 6 this year, discussed the photographs of the corona they had taken, and referred to the efforts made by Palisa with a vicw to discovering an intra-Mercurial planet, efforts which, as was well known, had yielded a negative result. Prof. Foerster gave an interesting account of observations made in the Berlin Observatory, by which he endeavoured to prove that the one ground-pillar of the Berlin Observatory on which investigations had hitherto been conducted had for the last twenty-five years been subjected to angular movements which were connected with the eleven years' period of solar spots. The annual averages of inclinations of the pillar from i 856 to $188 \mathrm{r}$ adhered as closely to Wolf's relative numbers as did the annual averages of the magnetic declination. From these facts Prof. Focrster drew the conclusion that very considerable effects could be traced from the radical changes of the eleven years' solar period. In connection with this communication of Foerster's, B. A. Gould reported how he had made quite similar observations on the sea-coast. Prof. Oppolzer (Vienna) spoke of investigations he had made in the Vienna Observatory with a view to determining the length of the seconds pendulum and the influence of the simultaneous oscillations of the stand. Foli gave an account of his examinations into the daily nutation and precession of the earth and his new tables of precession, and communicated some information regarding the observatory of Liege. Pechule (Copenhagen) sought to refute Stone's assertion that there was a difference of $1 \frac{1}{2}$ sec. between the former and the present Julian year, an assertion which had already been declared by Airy to be incorrect. He pointed out where Stone had committed an error in his calculations, and brought forward proof to show that the difference amounted to but four seconds every thousand years. Oudemans (Utrecht) corrected an assertion of Stone's that there was an error of $28 \mathrm{sec}$. in the reduction from median to sidereal time. Steinheil (Munich) referred to new constructions of telescopes calculated by him, and to the influence of the prism in the case of refracting telescopes on the sharpness of the image, in respect of the achromatism of the images, and to the means by which he counteracted the prejudicial effects in such cases.

On Sept. I 5 the members of the Congress visited the Observatory. The astronomers were highly satisfied with the arrangement of the observatory and the system of apparatus. The 27-inch instrument, supplied by Grubb of Dublin, and described in NATURE shortly after its completion, was an especial object of interest. Unfortunately the sky was clouded, so that it was impossible for the astronomers to carry out the observations they had intended with this powerful instrument. In reference to administrative matters we have also to mention Foerster's report on the conclusions of the International Commission respecting Kiel as an international centre, particularly in regard to the contributions of the respective astronomical institutes. On September 16 a social excursion was made to the neighbouring Kahlenberg, and this event was also made the occasion of the bapism of several newly discovered planets; the planet 234, discovered by Peters, rcceiving the name of Barbara; the three discovered by Palisa (Vienna) being called (229) Adelinda, (231) Vindobona, (225) Henrietta. It was resolved that the next meeting of the Society should be held at Geneva in 1885 .

\section{THE NORWEGIAN CIRCUMPOLAR STATION}

$\mathrm{I}^{\mathrm{T}}$ is with pleasure that $\mathrm{I}$ respond to the invitation of NATURE to give an account of our labours here during the last twelve months, and I may, in doing so, state that $I$ have purposely delayed writing these lines, in order to be able to give the result of our rescarches during a whole year.

The Norwegian Government have contributed their share to the international research of the physical conditions of the Polar regions by the establishment of the observatory here at Bossekop in Alten (Finmarken). The station, which is situated at the bottom of the Alten Fjord in $69^{\circ} 5^{8}$ lat. and $23^{\circ} 15^{\prime}$ long., commenced its labours on August 1, I882, which are to be continued until September I, 1883 , in accordance with the programme of the Polar Congress held in St. Petersburg in 188r. The equipment and instruments of the station, as well as its whole organisation, are also in accordance with the principles formulated by the Polar Congresses held in Hamburg in 1879 , in Bern in 1880 , and in St. Petersburg in $188 \mathrm{I}$. The personnel of the station consists of the writer as chief, Doctors C. Krafft, sub-chief, J. Schroeter and $\mathrm{F}$. Hesselberg, observers, and Herr O. Hagen, instrument maker and caretaker.

The obligatory observations embrace astronomical observations, readings every hour of the meteorological and magnetic variations, absolute measurements of the terrestrial current's three components, and studies of the aurora borealis. For the hourly observations the day and night have been divided into four watches of six hours each, which are taken by each one in turn.

In order to effect the astronomical observations, i.e. the determination of time and place, a small observatory $25 \mathrm{~m}$. in length, breadth, and height has been erected of deals, the roof and the southern and northern walls of which are provided with shutters to be opened during meridian observations. On a fixed pillar in the centre is placed a universal instrument by Repsold, besides which we possess three box chronometers by Frodsham, Kessels, and Mewes, the last named being regulated by star time, as well as two pocket chronometers by Kessels and Bröcking.

The weather during the winter and certain other circumstances have to some extent affected the astronomical observations, so that for the determination of time only a few meridian passages have been observed; but this circumstance is of no consequence whatever, as the station is independent of local determination of the time for ascertaining the absolute time, viz. the common mean time of Göttingen, which has been adopted at all the Polar stations as the common time, and which we receive from the observatory at Christiania through the telegraph office, about ten minutes distant, twice a week, at 9 a.m. on Sundays and 8 a.m. on Wednesdays, Greenwich time.

We have, however, a few meridian passages and observations of time with corresponding sun altitudes, which may be used for the verification of the longitude of the place. The Polar altitude has been verified by the measuring of circummeridian altitudes of the sun and Polaris. The universal instrument has also been employed for the determination of azimuth for the observations of the aurora borealis and the magnetic declination.

Of magnetical instruments we have a set for the determination of the elements of the terrestrial current, viz. a unifilar magnetometer by Elliott Brothers of London, and a Dover inclinatorium, both verified at Kew. The variation instruments, which are constructed on Lamont's principle by Prof. Mohn, and cxecuted by Herr C. Olsen, optician, of Christiania, consist of a variation instrument, a unifilar apparatus with two fixed deflectors for the observation of the variations of the horizontal intensity, and a unifilar apparatus with vertical bars of soft iron as deflectors, whose magnetic moment varies accord- 